\title{
Prey Limitation Drives Variation in Allometric Scaling of Predator-Prey Interactions
}

\author{
Raul Costa-Pereira, ${ }^{1,2,3, \star}$ Márcio Silva Araújo, ${ }^{2}$ Renan da Silva Olivier, ${ }^{4}$ Franco L. Souza, ${ }^{4}$ \\ and Volker H. W. Rudolf ${ }^{3}$
}

1. Programa de Pós-Graduação em Ecologia e Biodiversidade, Universidade Estadual Paulista (UNESP), Rio Claro, São Paulo, Brazil; 2. Instituto de Biociências, UNESP, Rio Claro, São Paulo, Brazil; 3. BioSciences, Rice University, Houston, Texas 77005; 4. Instituto de Biociências, Universidade Federal de Mato Grosso do Sul, Campo Grande, Mato Grosso do Sul, Brazil

Submitted February 5, 2018; Accepted April 6, 2018; Electronically published July 23, 2018

Online enhancements: appendix. Dryad data: http://dx.doi.org/10.5061/dryad.011v40v.

\begin{abstract}
Ecologists have long searched for a universal size-scaling constant that governs trophic interactions. Although this is an appealing theoretical concept, predator-prey size ratios (PPSRs) vary strikingly across and within natural food webs, meaning that predators deviate from their optimal prey size by consuming relatively larger or smaller prey. Here we suggest that this unexpected variation in allometric scaling of trophic interactions can be predicted by gradients of prey limitation consistent with predictions from optimal foraging theory. We analyzed $>6,000$ trophic interactions of 52 populations from four tropical frog species along a gradient of prey limitation. The mean of PPSR and its variance differed up to two orders of magnitude across and within food webs. Importantly, as prey availability decreased across food webs, PPSR and its variance became more size dependent. Thus, trophic interactions did not follow a fixed allometric scaling but changed predictably with the strength of prey limitation. Our results emphasize the importance of ecological contexts in arranging food webs and the need to incorporate ecological drivers of PPSR and its variance in food web and community models.
\end{abstract}

Keywords: food web, predator-prey size ratio, predator-prey mass ratio, trophic interactions, prey availability, size scaling.

\section{Introduction}

The structure and functioning of biological communities strongly depend on the distribution and characteristics of trophic links connecting predators and their prey in complex ecological networks (Paine 1966; Estes et al. 2011). One of the most striking patterns of predator-prey interactions is that they are inherently size structured (Emerson et al. 1994). Indeed, allometric scaling of predator-prey size relationships is one of the pillars of food web and metabolic

\footnotetext{
* Corresponding author; e-mail: raulcpereira@gmail.com. ORCIDs: Costa-Pereira, http://orcid.org/0000-0003-2370-5866; Araújo, http:// orcid.org/0000-0003-3533-744X; Rudolf, http://orcid.org/0000-0002-9214-2000.

Am. Nat. 2018. Vol. 192, pp. E000-E000. (C) 2018 by The University of Chicago. 0003-0147/2018/19204-58241\$15.00. All rights reserved.

DOI: $10.1086 / 698726$
}

theories (Brose et al. 2006b; Petchey and Dunne 2012; Kalinkat et al. 2013) and plays a key role in determining the stability and dynamics of natural food webs (Emmerson and Raffaelli 2004; Otto et al. 2007). However, identifying the general laws that govern the size scaling of predatorprey interactions has troubled ecologists for decades (Hatton et al. 2015).

An important concept to predict predator-prey interactions is the predator-prey size ratio (PPSR), which describes the relative size differences between predators and their prey. Theory predicts a preferred, intermediate optimal PPSR that maximizes energetic intake and interaction strength (Wootton and Emmerson 2005; Petchey et al. 2008; Brose 2010; Kalinkat et al. 2013). While the concept of a preferred predatorprey mass ratio is appealing, its application to food web theory is still problematic. For instance, current size-structured food web models and size-spectra community models assume a universal constant PPSR that can be applied to all predators (fig. 1a, right; Andersen and Beyer 2006; Petchey et al. 2008; Blanchard et al. 2009; Hartvig et al. 2011). This contrasts with empirical studies demonstrating that PPSRs (i) are highly variable across food webs (Brose et al. 2006a; Barnes et al. 2010) and (ii) can change with predator body size within food webs (i.e., size-dependent PPSRs; Brose et al 2006a; Barnes et al. 2010; Nakazawa et al. 2011; Nakazawa 2017). Specifically, in natural food webs, PPSRs tend to increase toward large-bodied predators; that is, large predators consume proportionally smaller prey (fig. $1 a$, left; Barnes et al. 2010; Nakazawa et al. 2011, 2013). This discrepancy between the theoretical concept of a universal size-scaling constant versus the natural variation in empirical systems suggests that we are likely missing key mechanisms that also play an important role in shaping predator-prey allometries (Tsai et al. 2016; Nakazawa 2017).

Here we suggest that much of the variation in PPSRs likely stems from ecological factors restricting optimal foraging via 
a Size-dependence of Predator-Prey size ratios (PPSR)

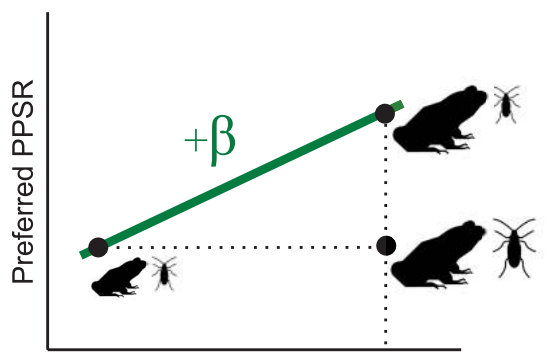

Individual predator size

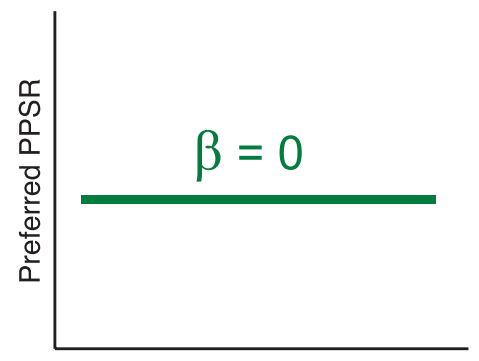

Individual predator size

\section{b Size-dependence of the variance in PPSR}

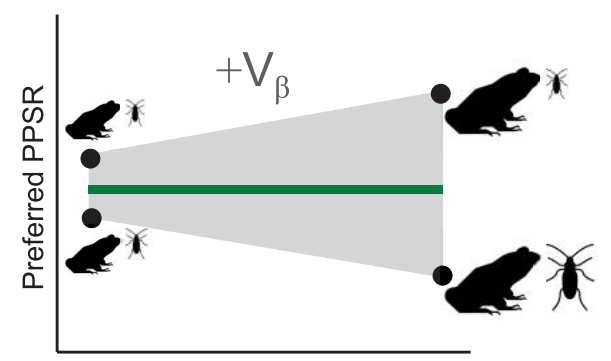

Individual predator size

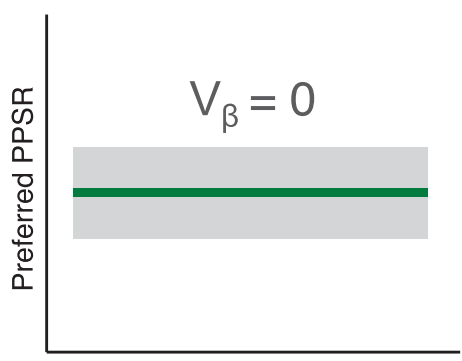

Individual predator size

Figure 1: Schematic view of how preferred predator-prey size ratio (PPSR) and its variance can change within a given food web. As commonly assumed by food web theory, PPSRs are invariant ( $a$, right $)$. Alternatively, empirical studies have found that commonly large predators tend to consume, on average, proportionally smaller prey, leading to a size-dependent PPSR $(a$, left $)$. Regarding the variance in PPSR $(b)$, food web theory implicitly assumes that the variance in PPSR is negligible and constant across large and small predators $(b$, right $)$. However, if the variance around PPSR scales with predator body size $(b, l e f t)$, large and small-sized predators differ in their degree of variation in foraging decisions regarding prey size.

prey availability. Theory predicting a single size ratio typically makes the implicit assumption that prey availability is unrestricted and constant across ecological scenarios (Nakazawa 2017). However, differences in environmental conditions across food webs - for example, variation in productivity, food web configuration, or density of competitors - can limit the abundance of ideal prey size, forcing predators to deviate from their optimal prey size ratio. Thus, the natural variation in size ratios might simply reflect the difference between optimal versus realized prey preferences under suboptimal availability (Tsai et al. 2016; Nakazawa 2017). Specifically, factors that increase prey limitation should force predators to include relatively smaller, less-profitable prey in the diet (Griffiths 1980; Barnard and Brown 1981; Nakazawa et al. 2011). Overall, this suggests that PPSRs should vary predictably across communities with ecological factors that drive prey availability, but this hypothesis remains untested.

Furthermore, environmental availability of prey is not homogeneous to all consumers within food webs or even within a consumer species. Larger predators inherently have a broader size range of potential prey (Wilson 1975; Wheelwright 1985;
Karpouzi and Stergiou 2003). Thus, the actual availability of prey for a given predator tends to increase with its body and gape sizes, and this difference could lead to size-dependent predator-prey ratios. Importantly, as the availability of potential resources depends on predator body size (due to gape limitation), prey size selection by small- and large-sized predators could respond differently across ecological contexts, which may constitute an underlying driver of the variation of size dependence of PPSRs commonly observed in natural food webs (Barnes et al. 2010; Nakazawa et al. 2011).

The same mechanisms altering the average scaling of predator-prey interactions should also change their variance around that average. Importantly, the variance in PPSRs provides an indication of the consistency of foraging decisions by predators within food webs, which has the potential to affect the stability of biological communities (Kalinkat et al. 2013). Therefore, ecological factors limiting prey availability might constrain the access to optimal prey size, leading to increased variance in size selection patterns. This effect should be stronger for large-sized predators within food webs because of their larger scope for diet variation (i.e., wider range 
of potential prey sizes), suggesting that the variance in size ratio might also scale predictably with consumer body size in natural food webs (fig. $1 b$, left). However, this hypothesis remains untested because previous studies focused solely on the average PPSRs of whole food webs, species, or size classes, implicitly assuming that variations in scaling patterns are negligible and size invariant (fig. 1a). Yet identifying whether and how variation in PPSRs changes across predator sizes and ecological contexts is essential to developing more realistic and accurate food web models.

Here we analyzed predator-prey size patterns across tropical food webs to understand how prey limitation affects the allometric scaling of trophic interactions. Specifically, we quantified prey availability and predator diets of all size classes of four congeneric amphibian predators across 52 populations to test the hypotheses that $(a)$ average PPSRs and $(b)$ variation around that mean should differ predictably across food webs and predator size. We predicted that food webs under low prey availability (i.e., low biomass of prey and high densities of conspecifics and heterospecifics) should present stronger size dependence of average PPSRs (positive relationship between predator body size and average PPSR). Accordingly, we also expect that resource limitation leads to a positive scale of the variance in size ratios with predator body size.

\section{Methods}

\section{Study System}

To examine the ecological drivers of predator-prey size scaling relationships, we analyzed trophic interactions in four congeneric thin-toed frog species (Leptodactylus bufonius, Leptodactylus chaquensis, Leptodactylus fuscus, and Leptodactylus podicipinus) in tropical lowland ponds. This is a suitable system for studying predator-prey interactions because thin-toed frogs vary largely in size within species and are trophic generalists, consuming a wide range of prey sizes (from tiny invertebrates to vertebrates; Piatti and Souza 2011; CostaPereira et al. 2015, 2018b). Moreover, these species are highly abundant in tropical communities and forage intensively at night during the summer, allowing us to recover a relatively large number of consumed prey (i.e., foraging events) from gut contents. Finally, frogs swallow their prey whole, enabling us to obtain direct and thus accurate measures of prey size from gut content data.

\section{Data Collection}

In the summer of 2014, we sampled 52 populations of thintoed frogs in an area covering $\sim 400 \mathrm{~km}^{2}$ of the Pantanal wetlands, central Brazil. Anurans were collected by hand in six $10 \times 10$-m plots (standard collection effort of $1 \mathrm{~h} /$ people $/ 100 \mathrm{~m}^{2}$ ). After the anuran survey, Leptodactylus spp. indi- viduals were euthanized with an overdose of analgesic (lidocaine) and then kept in a $-20^{\circ} \mathrm{C}$ freezer. Individuals from other species were identified and released in the same night of sampling. We collected prey locally available to each frog population using pitfall and light traps (see appendix, available online, for details on data collection).

We quantified predator body size by measuring the snout-vent length and body mass of each individual predator using a digital caliper $(0.01 \mathrm{~mm})$ and a precision scale $(0.001 \mathrm{~g})$, respectively. Predator length and mass ranged from 22.51 to $95.11 \mathrm{~mm}$ and from 0.97 to $69.95 \mathrm{~g}$, respectively. We obtained prey size measurements for each predator by dissecting frogs to retrieve their gut (both stomach and intestine) and analyze its contents under a stereomicroscope. We identified, counted, and measured the body size of all prey items found among the gut contents (table A1, available online). As frogs swallow their prey whole, most prey were found intact in the guts. For partly digested prey or body parts, we estimated body size using a reference collection from our environment samples. Highly digested prey were not considered in our analyses ( $1.73 \%$ of prey). To quantify resource availability in the environment, we counted, identified, and measured all prey collected from the field. We estimated the mass of each prey from length measurements using length-mass relationships generated from our environmental samples or literature (Sabo et al. 2002; Wardhaugh 2013). Overall, our individual-level data set includes 974 predator individuals, 6,172 observed trophic interactions, and 9,470 prey individuals available in the environment.

\section{A Novel Approach to Calculate PPSRs}

In the vast majority of previous studies, PPSRs are calculated from gut contents or foraging observations (i.e., dietary data). However, using only observed trophic interactions to obtain PPSR implicitly assumes that prey size composition in the environment does not affect prey selectivity by predators, which is an unreasonable assumption in natural food webs (Tsai et al. 2016; Nakazawa 2017). For example, if relatively large prey types are absent in a given site, the realized PPSR tends to be large not because predators are actively selecting smaller prey but because the local food availability constrains their foraging options.

To work around this problem, Tsai et al. (2016) proposed a method for quantifying preferred PPSR that accounts for how changes in environmental prey size distributions can affect relative prey size in predator diets. By comparing the magnitudes of realized PPSR (from gut contents) versus environmental PPSR (prey availability), it is possible to assess preferred PPSR. Deviations between realized and environmental PPSRs would indicate variation in relative prey size preference not associated with differences in environmental prey availability across food webs (Tsai et al. 2016). While this 
approach provides a more realistic measure of PPSR, it still assumes that the environmental availability of prey is equal to all predators. However, this is unlikely to hold true if there is enough body size variation across predators (e.g., ontogenetic variation, interspecific size differences) and across prey types. For example, small predators may not be physically able to consume the largest prey of a larger predator. Thus, even though the prey is technically available for both, it would be unreasonable to assume that the set of prey choices (i.e., environmental prey availability) is identical for the smalland large-sized predator.

Our method aims to overcome this shortcoming by incorporating gape limitation at the individual level in the calculation of preferred PPSR. As measures of body size, we considered length $(\mathrm{mm})$ or mass $(\mathrm{mg})$. However, because results for length- and mass-based metrics of PPSR were qualitatively the same, we describe only the results for the length-based metric because we directly measured length in predator and prey. The first step was to determine the relationship between predator body size and maximum prey size. Thus, we obtained the upper boundary of the feeding range by fitting the $95 \%$ quantile regression between $\log 10$ (predator body size) and $\log 10$ (prey size) across all species (results per species were quantitatively similar; Gravel et al. 2013). Using this allometric scaling model (intercept $=1.127, \beta=0.641$, length data; fig. A1; figs. A1-A6 are available online), we estimated the respective maximum size of a potential prey for each individual predator. We used this critical maximum prey size to restrict the size distribution of total local prey available, obtaining for each individual predator an actual size distribution of available prey (fig. A1). Then, we calculated the environmental $\operatorname{PPSR}_{i}$ (Tsai et al. 2016) for each individual predator $i$ by dividing $S_{i}$ (body size of individual predator $i$ ) by $m_{i}$ (median of the truncated size distribution of locally available prey). In turn, realized $\operatorname{PPSR}_{i}$ was calculated by dividing $S_{i}$ by $s_{j}$ (body size of individual prey $j$ ). As proposed by Tsai et al. (2016), preferred PPSR $_{i}$ is then obtained by subtracting $\log _{10}\left(\right.$ realized $\mathrm{PPSR}_{i}$ ) from $\log _{10}$ (environmental PPSR $)$ (see appendix for details). Our metric of preferred $\mathrm{PPSR}_{i}$ that incorporates gape limitation was well correlated with Tsai et al.'s (2016) metric $(r=0.85, P<.001)$, but for many individuals, particularly small-bodied predators, our metric resulted in remarkably lower estimated values of $\operatorname{PPSR}_{i}$ (fig. A4).

\section{Size Dependence of PPSRs}

For each studied population, we tested when and how PPSR varies with predator size using linear mixed models (normal error distribution), with preferred $\mathrm{PPSR}_{i}$ as the response variable, the size of a predator individual as the fixed effect, and the individual identity as the random effect (package lme4;
Bates et al. 2014). We used the resulting fixed coefficient (and respective standard error) as a metric of size dependence for each frog population. When $\beta=0, \mathrm{PPSR}_{i}$ is size independent, while $\beta>0$ or $\beta<0$ would indicate that $\mathrm{PPSR}_{i}$ is size dependent, with larger individuals including proportionally smaller or larger prey in their diets, respectively (fig. 1a). For this and the following analyses, we considered only populations with more than 10 individuals and with a range of predator body size higher than $12 \mathrm{~mm}$ (total size range: $22.51-95.11 \mathrm{~mm}$ ), which is sufficient to result in differences in gape size and prey consumption across predators (R. Costa-Pereira, personal observation).

\section{Variance in the Size Dependence of PPSRs}

To elucidate how the variance in $\operatorname{PPSR}_{i}$ scales with predator body sizes (fig. 1b), we calculated a metric based on successive quantile regressions that quantifies how differences in foraging decisions vary within a given predator size. Quantile regressions allow one to estimate multiple rates of change (slopes) between variables for all portions of a distribution of the response variable (Cade and Noon 2003). We can use this technique to fit regression curves to different parts of the distribution of observed $\mathrm{PPSR}_{i}$. If all individual predators exhibit exactly the same $\mathrm{PPSR}_{i}$, successive quantile regressions (e.g., 5\%, 50\%, and $100 \%$ ) result in models with very similar slopes $(\beta)$. However, as individual predators begin to deviate from average $\mathrm{PPSR}_{i}$, quantile regressions assume different slopes (fig. A2). The difference of estimated $\mathrm{PPSR}_{i}$ values by these successive quantile models thus estimate the variance in $\mathrm{PPSR}_{i}$ within predators with the same body size. Specifically, for each population, we fitted 21 successive quantile regressions ( $0.1 \%$ to $100 \%$, increments of $5 \%)$ with $\mathrm{PPSR}_{i}$ as response variable and predator body size as predictor using the quantreg package (Koenker et al. 2017). Then, to obtain estimates of variance in $\mathrm{PPSR}_{i}$ along the whole range of predator body sizes, we obtained 11 equidistant values of predator body-size values (quantile values of the body-size distribution) and then used the estimated quantile models to estimate values of $\operatorname{PPSR}_{i}$ for each of these predator body-size values (fig. A3). Next, we calculated the variance between estimated values of $\mathrm{PPSR}_{i}$ for the quantile regressions within a given predator size (for each of the 11 quantile body-size values). Finally, our metric of size dependence of the variance in $\mathrm{PPSR}_{i}$ is the slope of a linear regression model with the variance in $\mathrm{PPSR}_{i}$ as response variable and predator size as predictor. A positive slope $\left(\mathrm{V}_{\beta}\right)$ indicates a positive size dependence of the variance in $\operatorname{PPSR}_{i}$ (fig. $1 b$ ).

\section{Quantifying Prey Limitation}

We quantified three complementary ecological factors to represent variation in the intensity of competition and prey lim- 
itation across food webs. Following previous studies (e.g., Ward et al. 2006; Evangelista et al. 2014; Newsome et al. 2015), we considered the density of conspecific predators as a proxy for intraspecific competition. To represent the magnitude of interspecific competition, we calculated a metric of effective density of heterospecifics combining data on the local structure of frog communities and their phylogenetic relationships into the quantitative genetic competition model of Doebeli (1996; see appendix for details). This metric increases for a given population when locally co-occurring species are closely related and abundant. Finally, we quantified the total biomass of available prey at each food web.

\section{Hypotheses Testing}

We first tested which predator (species identity and body size) and prey (prey taxonomic identity) traits explain variation in PPSRs at the individual scale $\left(\mathrm{PPSR}_{i}\right)$ using linear mixed models in the package lme4 (Bates et al. 2014). We constructed five categories of statistical candidate models following Nakazawa et al. (2011): (i) null model, (ii) allometric model (predator size as fixed effect), (iii) taxonomic models (predator species identity or prey taxonomic group as fixed effect), (iv) combined models, and (v) full model (table 1). All these models included the population and individual identities as random factors. We compared candidate models using the difference in the corrected Akaike information criterion $(\triangle \mathrm{AICc})$ relative to the model with the lowest score, that is, the most parsimonious model.

To evaluate how differences in prey limitation across food webs affect the size dependence of PPSRs, we built mixedeffects meta-regression models in the package metafor (Viechtbauer 2010). This type of model has the advantage that it allowed us to incorporate standard errors in the estimate of our response variables $\left(\beta\right.$ and $\mathrm{V}_{\beta}$; fig. 1$)$. We included density of conspecifics, effective density of heterospecifics, and biomass of available prey as additive predictors and individual identity and site as random effects. We performed all data analyses in R 3.4.1. Data underlying the analysis are deposited in the Dryad Digital Repository: https://dx.doi.org/10.5061 /dryad.011v40v (Costa-Pereira et al. 2018a).

\section{Results}

\section{Variation in PPSRs}

In general, predators were 9.27 times longer and 266.56 times heavier than their prey (median values; see appendix for details), but there was a sizable variation in $\mathrm{PPSR}_{i}$ across individual predators (fig. A1; $\log 10$ transformed). For example, in some cases, predators were actually shorter than their respective prey (minimum realized $\mathrm{PPSR}_{i}=0.73$ ), while in other cases, predators were $>70$ times longer than their prey (maximum realized $\operatorname{PPSR}_{i}=72.76$ ). This tremendous variation in preferred PPSR $\mathrm{P}_{\mathrm{i}}$ was best explained by the model including individual predator body size and prey taxonomic identity (table 1). Although the full model including predator species identity performed equally well, only $1.3 \%$ of the total variance in $\mathrm{PPSR}_{\mathrm{i}}$ was attributed to predator identity $(\mathrm{df}=3$, $F=27.84)$.

\section{PPSR: Predator Size Relationship across Communities}

While preferred $\mathrm{PPSR}_{i}$ varied with predator body size overall (i.e., size-dependent PPSR), we found a striking shift

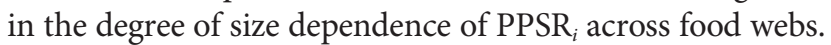
Observed patterns ranged from strong negative relationships between $\mathrm{PPSR}_{i}$ and predator body size in some sites (i.e., large predators consuming proportionally larger prey, $\beta<0$ ) to a weakly positive relationship (i.e., large predators consuming proportionally smaller prey, $\beta>0$; fig. 2 ). This variation in size dependency $(\beta)$ was significantly related to biomass of available prey but not to density of conspecifics and heterospecifics (table 2; fig. 3). As the biomass of food resources increased across food webs, PPSR $_{i}$ was less size dependent ( $\beta$ values approached 0$)$, meaning that small- and large-bodied individual predators tended to consume prey with proportionally similar sizes in high-resource biomass

Table 1: Candidate models to explain variation in predator-prey size ratios at the individual scale $\left(\mathrm{PPSR}_{i}\right)$ in thin-toed frogs (Leptodactylus spp.) using predator (species identity and body size) and prey (prey taxonomic identity) traits

\begin{tabular}{llr}
\hline Model & \multicolumn{1}{c}{ Formulation } & $\Delta$ AICc \\
\hline Combined model & PPSR $_{\mathrm{i}} \sim$ predator size + prey group & 0 \\
Full model & PPSR $_{\mathrm{i}} \sim$ predator size + predator spp. + prey group & .36 \\
Taxonomic model & $\mathrm{PPSR}_{\mathrm{i}} \sim$ predator spp. + prey group & 88.68 \\
Taxonomic model & $\mathrm{PPSR}_{\mathrm{i}} \sim$ prey group & 236.63 \\
Allometric model & $\mathrm{PPSR}_{\mathrm{i}} \sim$ predator size & $2,457.38$ \\
Combined model & $\mathrm{PPSR}_{\mathrm{i}} \sim$ predator size + predator spp. & $2,455.94$ \\
Taxonomic model & $\mathrm{PPSR}_{\mathrm{i}} \sim$ predator spp. & $2,549.62$ \\
Null model & $\mathrm{PPSR}_{\mathrm{i}} \sim 1$ & $2,664.76$ \\
\hline
\end{tabular}

Note: Here $\Delta \mathrm{AICc}$ represents the difference in the corrected Akaike information criterion (AICc) score relative to the model with the lowest value (most parsimonious model). 


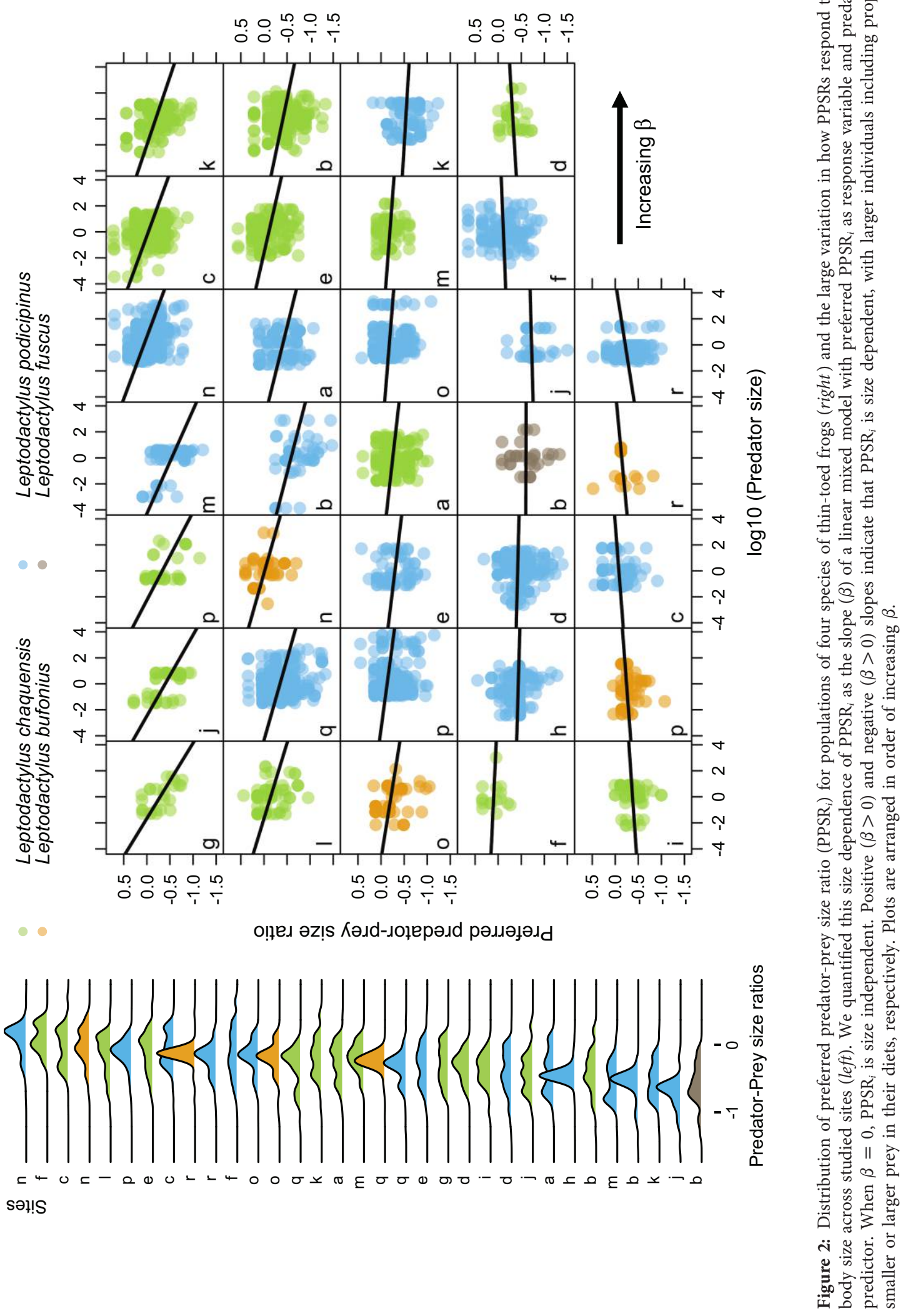

E000

This content downloaded from 128.042.167.031 on August 09, 2018 10:37:11 AM 
Table 2: Effects of density of conspecifics, effective density of heterospecifics, and total prey biomass on the degree of size dependence of predator-prey size ratio (PPSR) and its variance across populations of thin-toed frogs (Leptodactylus spp.)

\begin{tabular}{|c|c|c|c|c|c|c|}
\hline & \multicolumn{3}{|c|}{ Size dependence of PPSR } & \multicolumn{3}{|c|}{ Variance in size dependence } \\
\hline & Estimate (SE) & $z$ & $p$ & Estimate (SE) & $z$ & $p$ \\
\hline Intercept & $-.659(.41)$ & -1.6 & .11 & $-.029(.05)$ & .56 & .57 \\
\hline Density of conspecifics & $-.001(.01)$ & -.1 & .92 & $.002(.01)$ & 1.93 & .05 \\
\hline Effective density of heterospecifics & $-.005(.01)$ & -.26 & .79 & $-.002(.01)$ & -.69 & .48 \\
\hline Prey biomass & $-.164(.08)$ & 2.06 & .04 & $-.047(.01)$ & -3.13 & .001 \\
\hline
\end{tabular}

food webs. Overall, these results indicate that body-size ratios are not constant but instead change predictably with ecological context and predator size.

\section{Variance in PPSRs}

Variance in $\mathrm{PPSR}_{i}$ around the mean was not constant but instead changed with predator body size within food webs, and this relationship was strikingly different across food webs. (fig. A6). In some cases, large-bodied predators exhibited much more variation in their foraging choices than small predators $\left(\mathrm{V}_{\beta}>0\right)$, but in other food webs, there was no relationship or even the opposite trend $\left(\mathrm{V}_{\beta}<0\right.$; fig. $\left.\mathrm{A} 6\right)$. At least part of these differences in size-specific variation in $\operatorname{PPSR}_{i}$ was explained by density of conspecifics and total biomass of available prey (table 2; fig. 4). As the density of conspecifics increased and food biomass decreased across food webs (i.e., competition increased), large-bodied predators tended to exhibit proportionally larger variance in their consumed prey sizes when compared to small-sized predators. Overall, this indicates that variance in PPSR is not fixed within food webs, as commonly assumed by food web models, and can respond predictably to predator body size along prey limitation and productivity gradients.

\section{Discussion}

Predator-prey size ratios are key drivers of population and community dynamics and food web structure. Food web theory has traditionally assumed a single universal scaling of PPSRs based on metabolic principles (Brose et al. 2006b; Kalinkat et al. 2013). This tenet is inconsistent with variation in PPSRs with predator body size and across natural systems (Nakazawa et al. 2011), but it remains unclear what factors are driving this variation. Using a new method to quantify PPSRs that incorporates gape limitation of predators, we show that mean PPSRs (both in terms of length and mass) and variance around that mean change substantially across food webs and across predator body size within food webs. Both patterns in mean and variance of PPSRs were partially explained by a gradient of biomass of available resources, with populations subject to lower prey biomass (and thus stronger food limitation) exhibiting greater size dependence of PPSR. Together, these results demonstrate that there is no universal constant predator-prey size-scaling pattern in natural food webs but rather that it varies predictably with ecological contexts, such as competition for food resources. Moreover, our results show that variance in PPSRs is neither as negligible nor as constant as commonly assumed but instead depends on predator body size and the strength of
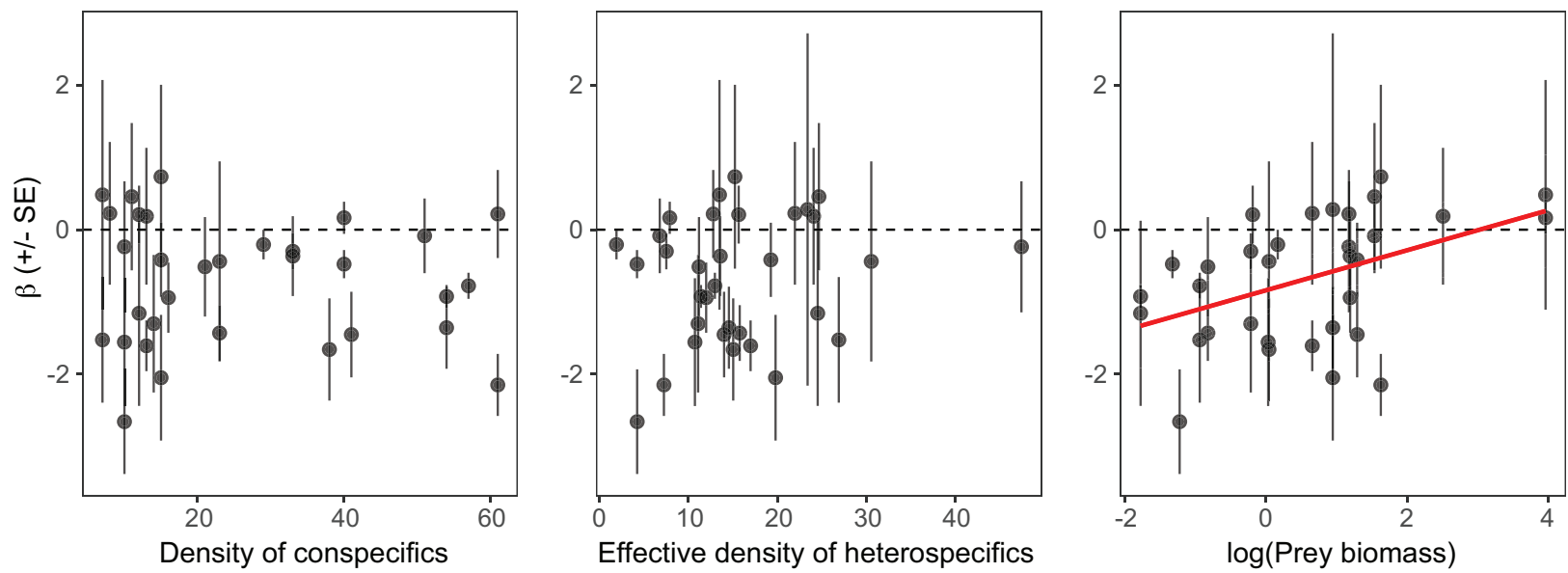

Figure 3: Effect of prey biomass - but not density of conspecifics and effective density of heterospecifics - on the degree of size dependence of average predator-prey size ratios in thin-toed frogs (Leptodactylus spp.). 

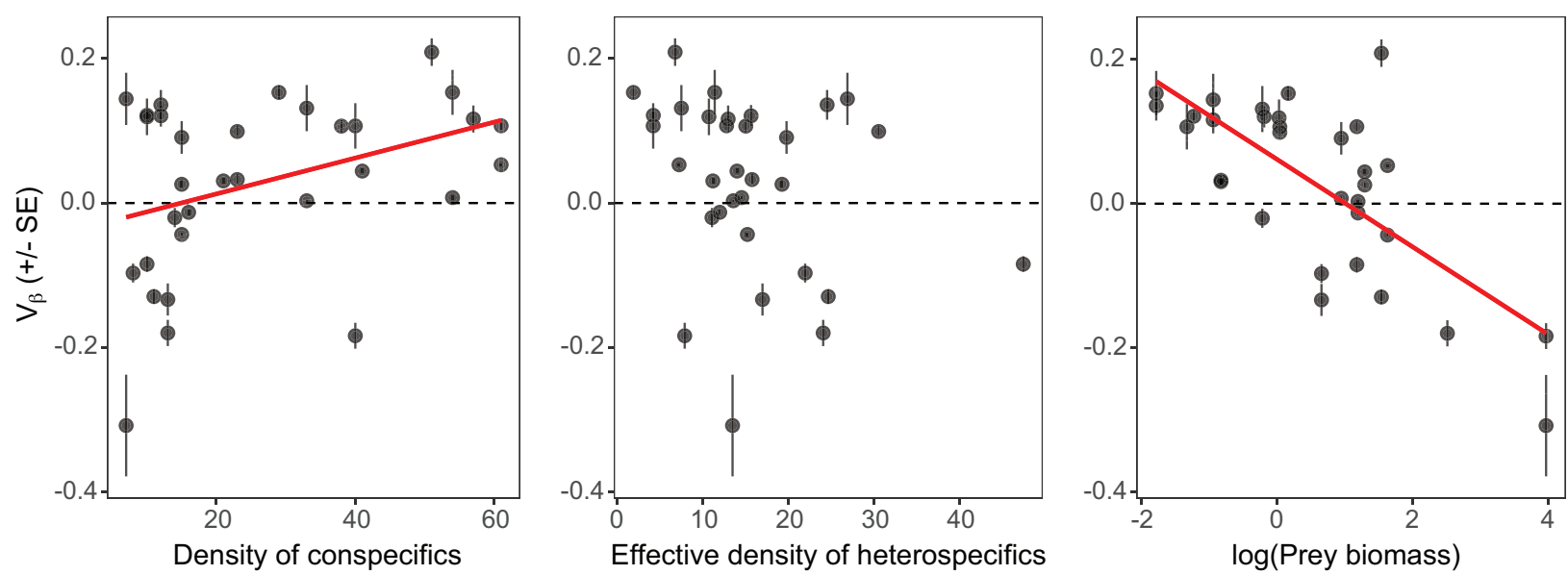

Figure 4: Effect of density of conspecifics and prey biomass—but not effective density of heterospecifics—on the degree of size dependence of the variance in predator-prey size ratios in thin-toed frogs (Leptodactylus spp.).

competition within a given ecosystem. Overall, our results emphasize the need to incorporate both ecological drivers of PPSR and variance of PPSR in food web and community models.

\section{Variation in PPSRs}

Inspired by metabolic theory, predator-prey studies often predict and search for universal power laws that can help explain and predict predator-prey interactions. In contrast, we found that PPSRs varied significantly across and within food webs by up to two orders of magnitude, emphasizing that trophic links do not follow one universal allometric relationship across this range of predator sizes. Consistent with previous studies (Barnes et al. 2010; Naisbit et al. 2011; Nakazawa et al. 2011), we found that part of this variation was linked to prey (taxonomic) identity and predator body size. This is not surprising given that traits of both predators and prey play an important role in determining the likelihood of trophic interactions, including encounter rates, handling time, and the ability to consume prey of a certain size (Sherry and McDade 1982; Chang et al. 2017; Uiterwaal et al. 2017).

Predators in our system encountered a large taxonomic and functional diversity of prey types ( $>14$ invertebrate families), and it is reasonable to expect that prey types exhibit differential vulnerability to predators (Woodward and Hildrew 2002; Boukal 2014; Uiterwaal et al. 2017). Unfortunately, our data did not allow us to identify which specific traits (e.g., offensive or defensive structures) confer lower or higher vulnerability to predation. Identifying these traits is an important next step to help explain and predict the importance of taxonomic identity in driving variation in PPSR (Klecka and Boukal 2013). Taxonomic identity of predators did not explain variation in PPSR, likely due to the ecological and morphological similarity among studied congeneric predator species (e.g., similar hunting behavior, morphology, trophic level). Predator identity should be a relevant driver of PPSR when it encompasses a wider taxonomic and functional range of organisms though (e.g., large spatial scales; Barnes et al. 2010; Nakazawa et al. 2011).

PPSR varied largely with predator body size for most of the food webs in our studied system. This size-dependent pattern is consistent with previous empirical studies (Barnes et al. 2010; Naisbit et al. 2011; Nakazawa et al. 2011) and likely arises because small- and large-sized predators experience environmental prey availability differently, resulting in the commonly observed size dependence of PPSR in natural communities. Importantly, our results indicate that the direction and strength of this size dependence is flexible and in part predictable across ecological contexts.

A key environmental factor contributing to the large variation observed in PPSRs (both across and within food webs) is prey availability. While prey availability is commonly equated to total prey abundance, it is important to keep in mind that actual prey availability is also dependent on individuals' gape limitation; that is, the gape of a predator determines the largest prey it can consume, imposing a biomechanical limit on available prey. As a consequence, studies relying on species-averaged predator and prey bodysize values are likely to misrepresent actual feeding relationships and underestimate the real variance in PPSRs in natural food webs, given that the vast majority of natural populations and ecological interactions are size structured (Woodward and Warren 2007; Nakazawa et al. 2011). Here we used a novel approach that specifically incorporates changes in prey availability with predator body sizes and identifies interactions that are morphologically unlikely (Jordano 2016). This 
approach demonstrates that traditional estimates that do not account for this gape limitation tend to overestimate preferred PPSRs for small-sized predators. Therefore, this biased overestimation of PPSR toward smaller predators may be an underlying reason for the negative relationship between predator body size and PPSR (i.e., size dependence of PPSR) commonly observed in natural food webs (Barnes et al. 2010; Nakazawa et al. 2011, 2013; see "Ecological Drivers of Size-Dependent PPSRs" below). Overall, these findings suggest that at least part of the current discussion on the variation and size dependence of PPSRs in natural systems may have underlying methodological sources, which can be amended by incorporating prey availability (Tsai et al. 2016) and gape limitation in PPSR estimates.

\section{Ecological Drivers of Size-Dependent PPSRs}

Intriguingly, two major bodies of theory in ecology diverge in a fundamental point: while food web and metabolic theories assume a universal scaling of PPSRs (Petchey et al. 2008; Petchey and Dunne 2012; Kalinkat et al. 2013), optimal foraging theory postulates that predators adjust their feeding decisions with changes in abundance of resources to maximize net energetic income across contexts (Stephens and Krebs 1986). Our results matched the theoretical expectation from the latter. As predators commonly select prey primarily by size (Werner and Hall 1974; Turner 1982), competition should deplete optimal-sized resources, shifting predator selectivity toward suboptimal resources (e.g., proportionally larger or smaller prey; Stephens and Krebs 1986). Accordingly, we found that the slope of the relationship between average PPSR and predator body size became flatter as available prey biomass increased (fig. 3). This pattern implies that, on average, foraging decisions are more divergent between smalland large-sized predators under prey limitation: large-bodied predators foraged on relatively larger prey than small-sized predators. This relationship could decrease niche overlap between conspecific individuals with different body sizes (e.g., ontogenetic niche shift), which can affect population and community persistence and dynamics (Miller and Rudolf 2011; Nakazawa 2015). Moreover, it suggests that regardless of body size, prey limitation forces predators to deviate from their optimal PPSR, emphasizing the context dependency of predator-prey size allometric scaling in natural food webs.

Our findings reveal that resource limitation may not only affect the average prey size selectivity of predators within natural food webs (i.e., size dependence of PPSR) but also its variance. Sites with high densities of conspecifics and low biomass of available prey exhibited a greater size dependence of the variance in PPSR, with large-sized predators exhibiting more variation in their foraging decisions than small ones. This pattern may be associated with the intrinsically higher scope for variation in prey size for large- sized predators because of their larger gapes. Therefore, if optimal-sized resources are depleted in high competition sites, large-sized predators have more alternative foraging options (i.e., proportionally smaller or larger prey) than small-sized predators, which could result in a stronger variance in PPSR toward larger individuals. This predictable density dependence of the scaling of the variance with body size is not yet included in food web models, but it can have important eco-evolutionary consequences and affect food web stability and functioning.

\section{Implications}

For the first time, we demonstrate that average predatorprey size ratios scale not only with predator size but with variance as well. Because diverse animal taxa are unable to mechanically reduce their prey before ingestion - including fish, amphibians, caecilians, and many reptiles and birds (Schwenk 2000)_our findings can have broad implications beyond the studied system. In fact, all predators (except group hunters, which represent a small proportion of predators in nature) are constrained from capturing prey larger than a critical body size, due, perhaps, to gape limitation but also, for example, reflecting ability to overcome and subdue prey. Further, as prey size influences fitness components in consumers, such as survival, lifetime, and fecundity (Griffiths 1980; Travis et al. 1985; Arsovski et al. 2014; Dodrill et al. 2016), our results suggest that prey limitation may affect predators' fitness landscapes by increasing the variation in foraging decisions among individuals. Importantly, prey size is a potential driver of rapid evolution in gape-constrained predators (Eloy de Amorim et al. 2017). Thus, understanding the drivers and magnitude of variation around the average PPSR in food web studies may bring new eco-evolutionary perspectives on food web theory. Furthermore, as food availability and density of competitors vary temporally and spatially in virtually all biological systems, our results emphasize that it is unreasonable to assume a single predator-prey scaling law for different ecological contexts. Food web models should therefore incorporate this context dependency of PPSR along gradients that affect prey limitation in natural systems (e.g., productivity, deforestation).

\section{Acknowledgments}

We thank B. Toscano and L. Sugai for comments on the manuscript; R. Kamiya for assistance with identification of gut contents; and L. Sugai, M. Uetabanaro, M. Sugai, S. Duleba, and R. Koroiva for help with fieldwork. We also thank the editor-in-chief, the associate editor, and two anonymous reviewers for their constructive comments. R.C.-P. was supported by São Paulo Research Foundation (FAPESP) grants (2014/20924-5, 2016/09038-9). M.S.A. is also grateful for 
FAPESP funding (grant 2010/15567-8). F.L.S. is supported by a Nacional de Desenvolvimento Científico e Tecnológico productivity grant (303006/2014-5).

\section{Literature Cited}

Andersen, K. H., and J. E. Beyer. 2006. Asymptotic size determines species abundance in the marine size spectrum. American Naturalist 168:54-61.

Arsovski, D., R. Ajtić, A. Golubović, I. Trajčeska, S. Đorđević, M. Anđelković, X. Bonnet, and L. Tomović. 2014. Two fangs good, a hundred legs better: juvenile viper devoured by an adult centipede it had ingested. Ecologica Montenegrina 1:6-8.

Barnard, C. J., and C. A. J. Brown. 1981. Prey size selection and competition in the common shrew (Sorex araneus L.). Behavioral Ecology and Sociobiology 8:239-243.

Barnes, C., D. Maxwell, D. C. Reuman, and S. Jennings. 2010. Global patterns in predator-prey size relationships reveal size dependency of trophic transfer efficiency. Ecology 91:222-232.

Bates, D., M. Maechler, B. Bolker, and S. Walker. 2014. lme4: linear mixed-effects models using eigen and S4. R package, version 1 . https://cran.r-project.org/web/packages/lme4/index.html.

Blanchard, J. L., S. Jennings, R. Law, M. D. Castle, P. McCloghrie, M.-J. Rochet, and E. Benoît. 2009. How does abundance scale with body size in coupled size-structured food webs? Journal of Animal Ecology 78:270-280.

Boukal, D. S. 2014. Trait- and size-based descriptions of trophic links in freshwater food webs: current status and perspectives. Iournal of Limnology 73.

Brose, U. 2010. Body-mass constraints on foraging behaviour determine population and food-web dynamics. Functional Ecology 24:28-34.

Brose, U., T. Jonsson, E. L. Berlow, P. Warren, C. Banasek-Richter, L.-F. Bersier, J. L. Blanchard, et al. 2006a. Consumer-resource body size relationships in natural food webs. Ecology 87:2411-2417.

Brose, U., R. J. Williams, and N. D. Martinez. 2006b. Allometric scaling enhances stability in complex food webs. Ecology Letters 9:1228-1236.

Cade, B. S., and B. R. Noon. 2003. A gentle introduction to quantile regression for ecologists. Frontiers in Ecology and the Environment 1:412-420.

Chang, C.-C., H. Y. Teo, Y. Norma-Rashid, and D. Li. 2017. Predator personality and prey behavioural predictability jointly determine foraging performance. Scientific Reports 7:40734.

Costa-Pereira, R., M. S. Araújo, R. Olivier, F. L. Souza, and V. H. W. Rudolf. 2018a. Data from: Prey limitation drives variation in allometric scaling of predator-prey interactions. Dryad Digital Repository, https://doi.org/10.5061/dryad.011v40v.

Costa-Pereira, R., V. H. W. Rudolf, F. L. Souza, and M. S. Araújo $2018 b$. Drivers of individual niche variation in coexisting species. Journal of Animal Ecology, doi:10.1111/1365-2656.12879.

Costa-Pereira, R., J. L. M. Sugai, S. Duleba, L. S. M. Sugai, J. Terra, and F. L. de Souza. 2015. Predation on Physalaemus centralis by Leptodactylus chaquensis. Herpetology Notes 8:345-346.

Dodrill, M. J., C. B. Yackulic, T. A. Kennedy, and J. W. Hayes. 2016. Prey size and availability limits maximum size of rainbow trout in a large tailwater: insights from a drift-foraging bioenergetics model. Canadian Journal of Fisheries and Aquatic Sciences 73:759-772.

Doebeli, M. 1996. A quantitative genetic competition model for sympatric speciation. Journal of Evolutionary Biology 9:893-909.
Eloy de Amorim, M., T. W. Schoener, G. R. C. C. Santoro, A. C. R. Lins, J. Piovia-Scott, and R. A. Brandão. 2017. Lizards on newly created islands independently and rapidly adapt in morphology and diet. Proceedings of the National Academv of Sciences of the USA 114: 8812-8816.

Emerson, S. B., H. W. Greene, and E. L. Charnov. 1994. Allometric aspects of predator-prey interactions. Pages 123-139 in P. C. Wainwright and S. M. Reilly, eds. Ecological morphology: integrative organismal biology. University of Chicago Press, Chicago.

Emmerson, M. C., and D. Raffaelli. 2004. Predator-prey body size, interaction strength and the stability of a real food web. Lournal of Animal Ecology 73:399-409.

Estes, J. A., J. Terborgh, J. S. Brashares, M. E. Power, J. Berger, W. J. Bond, S. R. Carpenter, et al. 2011. Trophic downgrading of planet earth. Science 333:301-306.

Evangelista, C., A. Boiche, A. Lecerf, and J. Cucherousset. 2014. Ecological opportunities and intraspecific competition alter trophic niche specialization in an opportunistic stream predator. Iournal of Animal Ecology 83:1025-1034.

Gravel, D., T. Poisot, C. Albouy, L. Velez, and D. Mouillot. 2013. Inferring food web structure from predator-prey body size relationships. Methods in Ecology and Evolution 4:1083-1090.

Griffiths, D. 1980. Foraging costs and relative prey size. American Naturalist 116:743-752.

Hartvig, M., K. H. Andersen, and J. E. Beyer. 2011. Food web framework for size-structured populations. Journal of Theoretical Biology 272:113-122.

Hatton, I. A., K. S. McCann, J. M. Fryxell, T. J. Davies, M. Smerlak, A. R. E. Sinclair, and M. Loreau. 2015. The predator-prey power law: biomass scaling across terrestrial and aquatic biomes. Science 349.

Jordano, P. 2016. Sampling networks of ecological interactions. Functional Ecology 30:1883-1893.

Kalinkat, G., F. D. Schneider, C. Digel, C. Guill, B. C. Rall, and U. Brose. 2013. Body masses, functional responses and predator-prey stability. Ecology Letters 16:1126-1134.

Karpouzi, V. S., and K. I. Stergiou. 2003. The relationships between mouth size and shape and body length for 18 species of marine fishes and their trophic implications. Lournal of Fish Biology 62:13531365 .

Kembel, S. W., P. D. Cowan, M. R. Helmus, W. K. Cornwell, H. Morlon, D. D. Ackerly, S. P. Blomberg, and C. O. Webb. 2010. Picante: R tools for integrating phylogenies and ecology. Bioinformatics 26:1463-1464.

Klecka, J., and D. S. Boukal. 2013. Foraging and vulnerability traits modify predator-prey body mass allometry: freshwater macroinvertebrates as a case study. Journal of Animal Ecology 82:1031-1041.

Koenker, R., S. Portnoy, P. T. Ng, A. Zeileis, P. Grosjean, and B. D. Ripley. 2017. Package "quantreg." Quantile regression. In 5. https:// cran.r-project.org/web/packages/quantreg/index.html.

Miller, T. E., and V. H. Rudolf. 2011. Thinking inside the box: communitylevel consequences of stage-structured populations. Trends in Ecology and Evolution 26:457-466.

Naisbit, R. E., P. Kehrli, R. P. Rohr, and L.-F. Bersier. 2011. Phylogenetic signal in predator-prey body-size relationships. Ecology 92: 2183-2189.

Nakazawa, T. 2015. Ontogenetic niche shifts matter in community ecology: a review and future perspectives. Population Ecology 57:347-354.

2017. Individual interaction data are required in community ecology: a conceptual review of the predator-prey mass ratio and more. Ecological Research 32:5-12. 
Nakazawa, T., S.-Y. Ohba, and M. Ushio. 2013. Predator-prey body size relationships when predators can consume prey larger than themselves. Biology Letters 9.

Nakazawa, T., M. Ushio, and M. Kondoh. 2011. Scale dependence of predator-prey mass ratio. Advances in Ecological Research 45:269-302.

Newsome, S. D., M. T. Tinker, V. A. Gill, Z. N. Hoyt, A. Doroff, L. Nichol, and J. L. Bodkin. 2015. The interaction of intraspecific competition and habitat on individual diet specialization: a near range-wide examination of sea otters. Oecologia 178:45-59.

Otto, S. B., B. C. Rall, and U. Brose. 2007. Allometric degree distributions facilitate food-web stability. Nature 450:1226-1229.

Paine, R. T. 1966. Food web complexity and species diversity. American Naturalist 100:65-75.

Petchey, O. L., A. P. Beckerman, J. O. Riede, and P. H. Warren. 2008. Size, foraging, and food web structure. Proceedings of the National Academy of Sciences of the USA 105:4191-4196.

Petchey, O. L., and J. A. Dunne. 2012. Predator-prey relations and food webs. Pages 86-98 in R. M. Sibly, J. H. Brown, A. KodricBrown, eds. Metabolic ecology. Wiley-Blackwell, Oxford.

Piatti, L., and F. Souza. 2011. Diet and resource partitioning among anurans in irrigated rice fields in Pantanal, Brazil. Brazilian Journal of Biology 71:653-661.

Pyron, A. R., and J. J. Wiens. 2011. A large-scale phylogeny of Amphibia including over 2800 species, and a revised classification of extant frogs, salamanders, and caecilians. Molecular Phylogenetics and Evolution 61:543-583.

Sabo, J. L., J. L. Bastow, and M. E. Power. 2002. Length-mass relationships for adult aquatic and terrestrial invertebrates in a California watershed. Journal of the North American Benthological Societv 21:336-343.

Schwenk, K. 2000. Feeding: form, function and evolution in tetrapod vertebrates. Academic Press, London.

Sherry, T. W., and L. A. McDade. 1982. Prey selection and handling in two Neotropical hover-gleaning birds. Ecology 63:1016-1028.

Stephens, D. W., and J. R. Krebs. 1986. Foraging theory. Princeton University Press, Princeton, NJ.

Travis, J., W. H. Keen, and J. Juilianna. 1985. The role of relative body size in a predator-prey relationship between dragonfly naiads and larval anurans. Oikos 45:59-65.
Tsai, C. H., C. H. Hsieh, and T. Nakazawa. 2016. Predator-prey mass ratio revisited: does preference of relative prey body size depend on individual predator size? Functional Ecology 30:1979-1987.

Turner, A. K. 1982. Optimal foraging by the swallow (Hirundo rustica, L): prey size selection. Animal Behaviour 30:862-872.

Uiterwaal, S. F., C. Mares, and J. P. DeLong. 2017. Body size, body size ratio, and prey type influence the functional response of damselfly nymphs. Oecologia 185:339. doi:10.1007/s00442-017-3963-8.

Viechtbauer, W. 2010. Metafor: meta-analysis package for R. R package, version 2010:1-0. https://cran.r-project.org/web/packages/metafor /README.html.

Ward, A. J. W., M. M. Webster, and P. J. B. Hart. 2006. Intraspecific food competition in fishes. Fish and Fisheries 7:231-261.

Wardhaugh, C. W. 2013. Estimation of biomass from body length and width for tropical rainforest canopy invertebrates. Australian Journal of Entomology 52:291-298.

Werner, E. E., and D. J. Hall. 1974. Optimal foraging and the size selection of prey by the bluegill sunfish (Lepomis macrochirus). Ecology 55:1042-1052.

Wheelwright, N. T. 1985. Fruit-size, gape width, and the diets of fruit-eating birds. Ecology 66:808-818.

Wilson, D. S. 1975. The adequacy of body size as a niche difference. American Naturalist 109:769-784.

Woodward, G., and A. G. Hildrew. 2002. Differential vulnerability of prey to an invading top predator: integrating field surveys and laboratory experiments. Ecological Entomology 27:732-744.

Woodward, G., and P. Warren. 2007. Body size and predatory interactions in freshwaters: scaling from individuals to communities. Pages 98-117 in A. Hildrew, D. Raffaelli, and R. Edmonds-Brown, eds. Body size: the structure and function of aquatic ecosystems. Cambridge University Press, Cambridge.

Wootton, J. T., and M. Emmerson. 2005. Measurement of interaction strength in nature. Annual Review of Ecology, Evolution, and Systematics 36:419-444.

Associate Editor: Jeremy W. Fox Editor: Daniel I. Bolnick

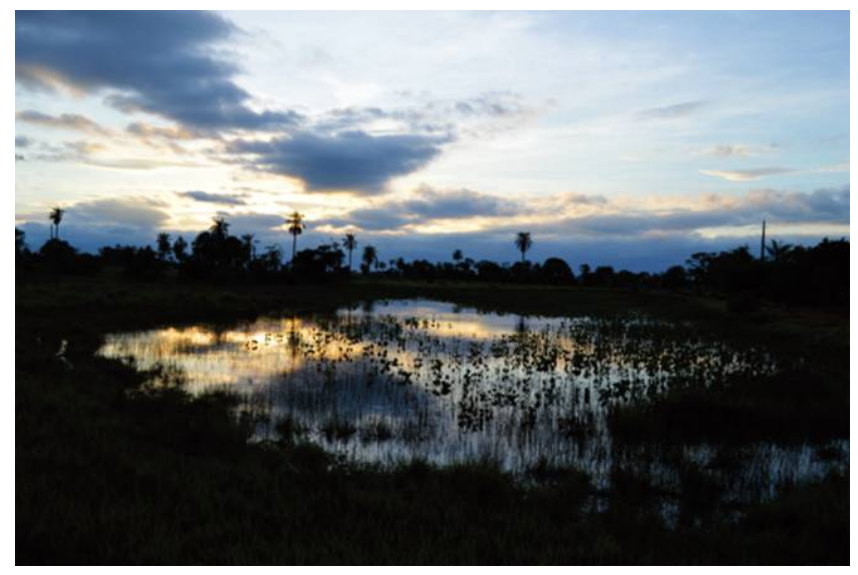

One of the sampled ponds in the Pantanal wetlands, central Brazil. Photo credit: Raul Costa-Pereira. 